\title{
Incidence, pattern and prognosis of brain metastases in patients with metastatic triple negative breast cancer
}

\author{
Jia Jin ${ }^{1,2+}$, Yu Gao ${ }^{1,2+}$, Jian Zhang ${ }^{1,2}$, Leiping Wang ${ }^{1,2}$, Biyun Wang ${ }^{1,2}$, Jun Cao ${ }^{1,2}$, Zhimin Shao ${ }^{2,3}$ \\ and Zhonghua Wang ${ }^{1,2,4^{*}}$ (D)
}

\begin{abstract}
Background: To identify the incidence, recurrence pattern and prognosis of brain metastases (BM) among women with metastatic triple negative breast cancer (mTNBC) treated consecutively at a single institution during a 7-year period.

Methods: Patients with histologically confirmed MTNBC were retrospectively identified. The incidence of BM as first site of recurrence and the cumulative BM incidence were computed. We used the Cox proportional hazards model to identify the univariate and multivariate factors associated with survival.

Results: Four hundred thirty three patients were included with a median overall survival (OS) of 21.6 months after median follow-up for 48.1 months. BM was found in 29\% (127/433) of the patients and about a quarter (32/127) of BM was first recurrence. The cumulative incidence of BM at 1 and 2 years was 17 and 25\%, respectively. The median time from the diagnosis of extracranial metastases to BM was 10 months. Median OS following a diagnosis of BM was 7.3 months. The longer median OS from time of first recurrent BM was noted compared with those of subsequent recurrent (17.3 vs 6.3 months, $p=0.008$ ). However, patients with first recurrent BM were associated with shorter OS compared with those without BM (17.3 vs 22.1 months, $p=0.006)$. The independent factors that increased BM death risk were $>3$ brain lesions, no BM-directed treatment, subsequent recurrent BM, symptomatic $\mathrm{BM}$ and uncontrolled extracranial metastasis.
\end{abstract}

Conclusions: Patients with mTNBC have a high incidence of early BM with subsequent poor survival. The findings lend support to consideration of screening imaging of the brain for mTNBC patients.

Keywords: Triple-negative breast cancer, Brain metastases, Prognosis, Recurrence pattern

\section{Background}

Breast cancer is the most frequently diagnosed tumor and the second leading mortality in female world [1]. It is also the second most common solid malignancy to metastasize to the brain, estimated to be present at the time of diagnosis of breast cancer in $0.41 \%$ of patients, constituting $7.56 \%$ of all metastatic sites [2, 3]. Another case series had reported the estimated incidence of brain

\footnotetext{
* Correspondence: zhonghuawang95@hotmail.com

${ }^{\dagger}$ Equal contributors

'Department of Medical Oncology, Fudan University Shanghai Cancer Center, Shanghai 200032, People's Republic of China

${ }^{2}$ Department of Oncology, Shanghai Medical College, Fudan University,

Shanghai, People's Republic of China

Full list of author information is available at the end of the article
}

metastasis $(\mathrm{BM})$ patients with metastatic breast cancer (MBC) ranged from 10 to $16 \%$ [4]. The development of $\mathrm{BM}$ remains one of the intractable problem for patients with $\mathrm{MBC}$ that results in poor morbidity and high mortality. Neurological impairments affected both cognitive and sensory functions and after the diagnosis of BM, the mortality within 1 year was about $80 \%[4,5]$.

The risk of BM has been shown to correlate with breast cancer subtype, and patients with triple negative or Human epidermal growth factor receptor-2 (HER2)positive subtypes experience significantly higher BM occurrence than patients with luminal-like disease [6-10], having a 3.5-3.6 fold increased risk compared with that of luminal tumors $[2,9,11]$. A study from Dana-Farber

(c) The Author(s). 2018 Open Access This article is distributed under the terms of the Creative Commons Attribution 4.0 International License (http://creativecommons.org/licenses/by/4.0/), which permits unrestricted use, distribution, and 
Cancer Institute of 116 metastatic triple negative breast cancer (mTNBC) had an increased probability of BM with an estimated risk as high as $46 \%$ prior to death [12]. Morever, prognosis after BM occurrence is also subtype-dependent. If patients with triple negative breast cancer (TNBC) develop recurrence, the subsequent survival is poor. TNBC patients had a strongly shorter median survival after BM than in the HER2- positive subtype [13-16]. Identification of biological and prognostic features associated with $\mathrm{mTNBC}$, and development of effective therapeutic strategies for this aggressive subtype of breast cancer are needed.

We aimed to calculate the incidence of BM, to describe the recurrence pattern of $\mathrm{BM}$, to analyse the outcomes after BM relapse and define the implications for prognostic factors of $\mathrm{mTNBC}$ patients in a large cohort at one single institution.

\section{Methods}

Patient data at Fudan University Shanghai Cancer Center were collected with the approval of the institution review board and were maintained in a confidential manner.

Medical records ranging from Jan 1, 2010 to Dec 31, 2016, covering a 7-year span, was included for review and extraction based on the following criteria: Patients with histologically confirmed mTNBC, documented based on immunohistochemistry (IHC) with estrogen receptor (ER) negative (IHC <1\%), progesterone receptor (PgR) negative (IHC < 1\%), and HER2 negative. HER2 status was assessed by IHC and/or fluorescence in situ hybridization (FISH). HER2 negative was defined as no staining by IHC, and HER2 gene amplification by FISH was performed for those cases of $2+$ by IHC and confirmed absence of gene amplification. Main exclusion criteria were bilateral breast cancer, other invasive malignant diseases within the past 5 years except excised basal cell skin carcinoma and cervical carcinoma in situ [5].

All patient identifiers were removed from the dataset, and no personal information on any patient or treating physician could be obtained. All the information available in the dataset was used exclusively for the purpose of this study and was not shared. Two investigators reviewed and extracted all relevant data independently, using standardized data extraction forms. Clinical characteristics, pathologic characteristics, imaging studies, treatment methods, and survival information were obtained. Survival data collected included date of death or periodical survival follow-up call per hospital routine or requirement of clinical trials. Disagreements were resolved by discussion with an independent expert.

The date of diagnosis of BM was based on the radiologic scan date. Overall survival (OS) was calculated from the date of diagnosis of mTNBC to date of death from any cause or last follow-up. Survival subsequent to the development of BM was measured from the date of $\mathrm{BM}$ to date of death from any cause or last follow-up. All patients alive at the time of the analysis were censored using the date of last follow-up.

All data was analyzed retrospectively. The KaplanMeier method was used for survival analysis and the cumulative BM incidence at 1 and 2 years. Differences between the Kaplan-Meier curves were evaluated using the log-rank test. Actuarial curves were compared by the two-tailed log-rank test and difference of $p<0.05$ was considered significant. Univariate and multivariate factors associated with survival were analyzed using the Cox proportional hazards model. The estimates of the models are given as hazard ratio (HR) with 95\% confidence intervals (95\% CI). All statistic analyses were performed using SPSS 17.0 software (SPSS Inc., Chicago, IL, USA).

\section{Results}

\section{Patient and tumor characteristics}

A total of $433 \mathrm{mTNBC}$ patients who were admitted to our hospital consecutively between Jan 1, 2010 to Dec 31, 2016 were identified. The median follow-up time of this study was 48.1 months (range, 5.7-78.7 months). General characteristics of these patients are summarized in Table 1. Median age at diagnosis of mTNBC was 48 years old (range: $23-78$ years), with 97 (22\%) patients $\leq 40$ years, while 286 (66\%) were pre- or perimenopause. The most common pathology were invasive ductal carcinoma (97\%) and grade III disease (77\%). Three hundred eighty one patients $(88 \%)$ had non-metastatic primary breast cancer who later developed metastatic disease while 52 (12\%) presented with stage IV mTNBC at initial diagnosis. Among early stage breast cancer, $351(92 \%)$ of the patients received neo/adjuvant chemotherapy, 323 (85\%) had received anthracyclinecontaining regimen; 268 (70\%) had received taxanes and anthracycline neo/adjuvant regimen. After the diagnosis of breast cancer, 114 (26\%) patients developed recurrence with one year. Thirty-seven ( $9 \%$ ) had $\geq 3$ metastatic organ sites while visceral involvement was noted in 252 (58\%) patients.

\section{Development of brain metastases in patients with mTNBC} $29 \%(127 / 433)$ of the patients developed BM, among whom about a quarter $(32 / 127)$ presented $\mathrm{BM}$ at initial diagnosis of mTNBC. About half (14/32) of patients in the "first recurrent BM group" had synchronous extracranial metastases. The most common involved sites were lymph nodes $(n=14)$, lung $(n=11)$, bone $(n=8)$, and liver $(n=5)$. The cumulative incidence of BM at 1 and 2 years was $17 \%$ and $25 \%$, respectively. The median 
Table 1 Patient Characteristics at Baseline $(N=433)$

\begin{tabular}{|c|c|c|}
\hline Characteristics & No. & $\begin{array}{l}\text { Percentage } \\
(\%)\end{array}$ \\
\hline \multicolumn{3}{|l|}{ Age, years } \\
\hline Median (Range) & $48(23-78)$ & \\
\hline$\leq 40$ & 97 & 22.2 \\
\hline$>40$ & 336 & 77.8 \\
\hline \multicolumn{3}{|l|}{ Menopausal status } \\
\hline Pre- or perimenopause & 286 & 66.0 \\
\hline Postmenopause & 138 & 31.9 \\
\hline Unknown & 9 & 2.1 \\
\hline \multicolumn{3}{|l|}{ Histological subtype } \\
\hline Invasive ductal & 419 & 96.8 \\
\hline Lobular & 6 & 1.4 \\
\hline Metaplastic & 6 & 1.4 \\
\hline Medullary & 2 & 0.5 \\
\hline \multicolumn{3}{|l|}{ Grade } \\
\hline$|-| \mid$ & 100 & 23.1 \\
\hline III & 333 & 76.9 \\
\hline \multicolumn{3}{|l|}{ DFI } \\
\hline$\leq 1$ year & 114 & 26.3 \\
\hline$>1$ year & 267 & 61.7 \\
\hline IV & 52 & 12.0 \\
\hline \multicolumn{3}{|l|}{ Prior neo/adjuvant chemotherapy } \\
\hline Anthracycline-containing regimen & 323 & 84.8 \\
\hline Anthracycline and Taxanes regimen & 268 & 70.3 \\
\hline Cyclophosphamide & 340 & 89.2 \\
\hline \multicolumn{3}{|l|}{ Initial site of mTNBC } \\
\hline Lymph nodes & 247 & 57 \\
\hline Liver & 101 & 23.3 \\
\hline Lung & 183 & 42.3 \\
\hline Bone & 105 & 24.3 \\
\hline Pleural effusion & 52 & 12 \\
\hline Local recurrence & 105 & 24.2 \\
\hline Brain & 32 & 7.4 \\
\hline Contralateral breast & 2 & 0.5 \\
\hline \multicolumn{3}{|l|}{ Visceral metastasis } \\
\hline Yes & 252 & 58.2 \\
\hline No & 181 & 41.8 \\
\hline \multicolumn{3}{|l|}{ Number of metastatic organ sites } \\
\hline$\geq 3$ & 37 & 8.5 \\
\hline$<3$ & 396 & 91.5 \\
\hline
\end{tabular}

DFI disease free interval

time from the diagnosis of extracranial metastases to BM was 10 months (95\% CI, 8.7-11.4).

Seventy-six patients $(60 \%)$ had symptomatic brain metastasis. The most common symptoms of BM were headache (40\%), vomiting (23\%), motor impairment $(12 \%)$, and vertigo (7\%).

Sixty-nine $(54 \%)$ patients had three or fewer brain lesions, and 58 (46\%) had more than three lesions. Intracranial metastases were located in the supratentorial region in 65 patients (51\%), in the infratentorial region in 12 patients $(9 \%)$, in both supra-and infratentorial regions in $30(24 \%)$, in the brainstem in 6 patients (5\%), and 14 patients $(11 \%)$ had meninges involvement. Sixtynine patients $(54 \%)$ had limited intracranial metastases (number of metastases $\leq 3$ ).

\section{Survival following brain metastases and prognostic factors}

At the time of the analyses, 298 (69\%) patients had died and OS at 1 and 2 years was 72 and 44\%, respectively. For the total 433 mTNBC patients, median OS was 21. 6 months (95\% CI 19.5-23.7) (Fig. 1a). Among the 127 patients who developed BM, 103 (81\%) had died. Initial treatment was whole-brain radiation therapy (WBRT) in 74 patients $(58 \%)$, stereotactic radiosurgery (SRS) in 7 patients (6\%), WBRT and SRS in 8 patients (6\%), surgical resection in 9 patients (7\%) and 29 patients (23\%) did not receive any treatment for $\mathrm{BM}$. A total of $16(50 \%)$ patients received platinum, 16 (50\%) patients received gemcitabine, $8(25 \%)$ patients received taxanes, $10(31.2 \%)$ patients received capecitabine and $1(3 \%)$ patient received bevacizumab as part of the treatment of mTNBC in the "first recurrent BM group". And the patients with first recurrence without $\mathrm{BM}$ had more chances to subsequent chemotherapies. The proportion of patients received platinum, gemcitabine, taxanes, capecitabine and bevacizumab was 288 (71.8\%), 342 (85.3\%), 233 (58.1\%), 175 (43. $6 \%)$ and $64(16.0 \%)$ patients, respectively.

Thirty-seven patients (36\%) died from intracranial disease. Twenty-nine patients (28\%) died due to progression of extracranial disease and their BM were controlled at the time of death. Thirty-six patients (35\%) died from progression of both intracranial and extracranial disease. One patient died from sepsis.

Median survival following the occurence of BM was 7 . 3 months (95\% CI, 6.1-8.4) (Fig. 1b) and OS at 1 and 2 years was 36 and $15 \%$, respectively. Among the 32 patients who developed BM at mTNBC presentation, 23 have died. Among other 401 patients whose first metastasis was extracranial metastases, 275 have died. Median OS from time of BM as first recurrence was longer compared with subsequent recurrence (17.3 vs 6.3 months, $p=0.008$ ) (Fig. 1c). However, patients with first recurrent $\mathrm{BM}$ were associated with shorter OS (17.3 months, 95\% CI 9.0-25.7) compared with those without first BM recurrence absence (22.1 months, 95\% CI 19.9-24.3) ( $p$ $=0.006)$ (Fig. 1d). 


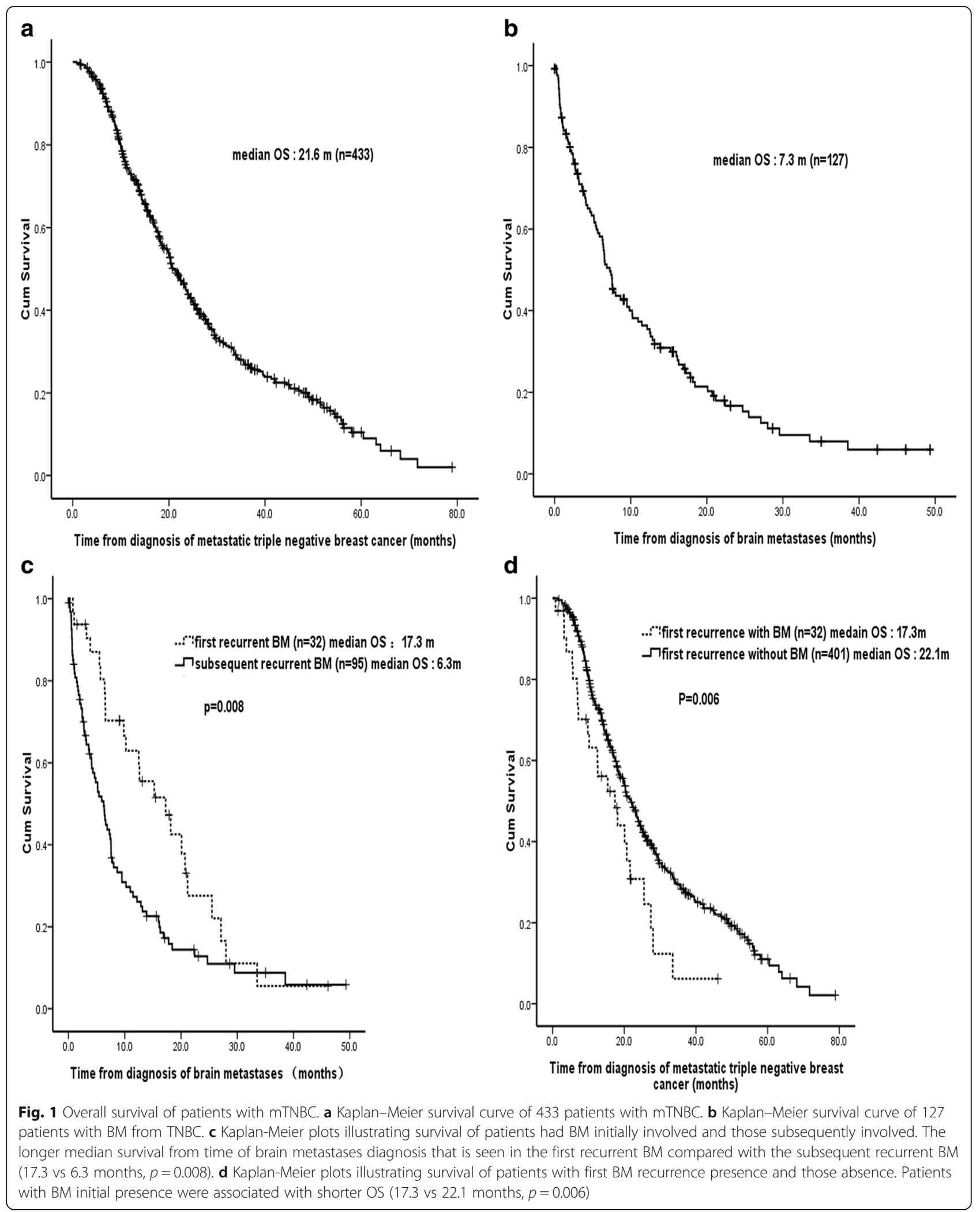


Univariate and multivariate regression analyses identified prognostic factors for survival (Table 2). The independent factors that increased $\mathrm{BM}$ death risk were $>3$ brain metastasis (HR: 2.37, 95\% CI: $1.47-3.80 ; p=0.001$ ) , no BM-directed treatment (HR: 2.30, 95\% CI: 1.32-3. 92; $p=0.002$ ), BM as the subsequently involved (HR: 2 . 21, 95\% CI: $1.18-4.17$; $p=0.01$ ), symptomatic brain metastasis (HR: 1.92, 95\% CI: 1.13-3.27; $p=0.01$ ) and uncontrolled extracranial metastasis (HR: 1.78, 95\% CI: 1. $13-2.92 ; p=0.02)$.

\section{Discussion}

In this study, we describe the incidence of BM among 433 patients with mTNBC and characterize the subsequent survival of such patients. BM was found in $29 \%$ of patients prior to death and about a quarter of BM was first recurrent at the time of diagnosis of metastatic disease. Median survival time following a diagnosis of BM was 7.3 months and patients with BM who were asymptomatic, with 1-3 metastases, received locoregional treatment, presented as first recurrence or controlled extracranial metastasis were independent predictors of better survival.

Patient-, disease- and treatment-related factors have effects on the prognosis of BM from breast cancer. Our findings are consistent with the modified breast graded prognostic assessment (breast-GPA) [17], based on a prospectively maintained institutional database $(n=$ 1552). The authors suggested number of BM (> 3 vs. $\leq 3$ ) is a strong and independent prognostic factor, besides age, tumor subtype, and Karnofsky performance status (KPS). In a study of 1256 patients with BM for breast

Table 2 Univariate and multivariate models for OS with BM in mTNBC patients $(n=127)$

\begin{tabular}{|c|c|c|c|c|c|c|c|}
\hline \multirow[b]{2}{*}{ Factor } & \multirow[b]{2}{*}{ No. } & \multicolumn{3}{|c|}{ Univariate } & \multicolumn{3}{|c|}{ Multivariate } \\
\hline & & Median & $95 \% \mathrm{Cl}$ & $P$ & $\mathrm{HR}$ & $95 \% \mathrm{Cl}$ & $P$ \\
\hline Age & & & & 0.55 & & & \\
\hline$\leq 40$ & 29 & 6.4 & $1.7-11.1$ & & & & \\
\hline$>40$ & 98 & 7.3 & $6.1-8.5$ & & & & \\
\hline DFI & & & & 0.33 & & & \\
\hline$\leq 1 y$ & 31 & 7.6 & $4.7-10.5$ & & & & \\
\hline$>1 y$ & 76 & 7.6 & $4.5-11.7$ & & & & \\
\hline IV & 20 & 5.4 & & & & & \\
\hline KPS & & & & 0.000 & & & 0.07 \\
\hline $70-100$ & 109 & 7.6 & $4.7-10.4$ & & 1.81 & & \\
\hline $40-60$ & 18 & 1.7 & $0.2-3.4$ & & & & \\
\hline Recurrent BM & & & & 0.008 & & & 0.01 \\
\hline First & 32 & 17.3 & $9.2-25.3$ & & 2.21 & $1.18-4.17$ & \\
\hline Subsequent & 95 & 6.3 & $4.5-8.0$ & & & & \\
\hline Number of intracranial metastases & & & & 0.002 & & & 0.001 \\
\hline$>3$ & 58 & 5.4 & $2.1-8.7$ & & 2.37 & $1.47-3.80$ & \\
\hline$\leq 3$ & 69 & 10.2 & $6.3-14.1$ & & & & \\
\hline Symptomatic brain metastasis & & & & 0.02 & & & 0.01 \\
\hline Presence & 76 & 5.5 & $2.8-8.2$ & & 1.92 & $1.13-3.27$ & \\
\hline Absence & 51 & 8.7 & $3.0-16.7$ & & & & \\
\hline Meninges involvement & & & & 0.01 & & & 0.48 \\
\hline Yes & 14 & 3.2 & $0.9-5.4$ & & 1.32 & $0.61-2.83$ & \\
\hline No & 113 & 7.6 & $4.8-10.3$ & & & & \\
\hline Brain-directed treatment & & & & 0.001 & & & 0.002 \\
\hline Not performed & 29 & 3.7 & $0.2-7.7$ & & 2.30 & $1.32-3.92$ & \\
\hline Performed & 98 & 9.5 & $6.3-12.7$ & & & & \\
\hline Extracranial metastasis ${ }^{a}$ & & & & 0.002 & & & 0.02 \\
\hline Under-control & 37 & 9.8 & $5.8-13.8$ & & 1.78 & $1.13-2.92$ & \\
\hline Out-of-control & 65 & 3.6 & $2.2-4.9$ & & & & \\
\hline
\end{tabular}

${ }^{\mathrm{a}} 103$ patients died 
cancer from 24 member institutions in Japan and a recent study focused on patients with brain-only metastases from breast cancer, several prognostic factors for longer survival were identified in multivariate regression analysis, including asymptomatic brain disease and active treatment of BM $[10,18]$. In addition to molecular subtype, the cumulative number of extracranial lesions is another risk factor for BM development among patients with metastatic disease. The risk of $\mathrm{BM}$ is significantly higher in patients with metastatic disease that involved more than 3 extracranial sites, including bone, lung, and liver (vs 0 or 1 site; odds ratio, $3.40 ; p<0.001$ ) [3]. In early breast cancer setting, historical data suggest risk factors for BM included young age, lymph node positive, grade 3 , TNBC or HER2 positive.

TNBC typically carried increased risk for early distant metastases, higher incidence of lung and brain involvement, and overall poorer survival outcome, as more characteristics of TNBC had been demonstrated and validated. Our findings are consistent with previous data indicating a higher propensity of approximately 30 to 46\% mTNBC patients will eventually develop BM prior to death $[19,20]$, while the frequency was about $10 \%$ in luminal tumors $[12,21]$. In addition, TNBC is also associated with higher risk (3.5 - 4.7\%) of developing BM as first site of recurrence, compared with non-selected breast cancer patients $(1.3 \%)[22,23]$. This may be the result of the inherent aggressiveness of TNBC, the predominance of infiltrative basal-like type. And because systemic chemotherapy does not adequately cross the blood brain barrier, the brain can be a sanctuary [24].

This current study showed that a high proportion of TNBC patients (up to 7.4\%) are diagnosed with BM at the time of initial metastatic diagnosis, and was consistent with a previous report. Several studies reported TNBC showed the shortest interval from primary early breast cancer to development of BM. Heitz F et al. [7] previously reported that shortest interval for triplenegative patients (22 months), and longer intervals for HER2-positive (30 months) and ER+/HER2- (63. 5 months) breast cancer. In larger sample size, our results are further validated by previous studies that patients with BM development in TNBC subtype displayed a dismal median survival of 3.7-7.2 months [2, 10, 13, $15,18,22,24]$, whereas HER2-positive and HR+/HER2 - subtypes displayed median survival 16.5-27.9 months and 9.3-14.0 months [2, 25, 26], respectively.

One notable finding was, however, in contrary to previous reports stating that patients with $\mathrm{BM}$ at initial diagnosis carried poor prognosis (Dawood et al. [22] reported only 5.8 months), we reported for the first time that the median survival for patients with first recurrent $\mathrm{BM}(n=32)$, was significantly longer than those with subsequent BM $(n=95), 17.3$ months vs 6.3 months, $p=0.008$. The potential causes are analyzed as follows. First, patients with $\mathrm{BM}$ as the first site of metastasis may have good KPS. On the contrary, the presence of extracranial disease of subsequent BM may play an important part in the whole disease. Because extracranial disease may have implications on organ function and choice of systemic therapy. Second, in our study, 14 (44\%) of 32 patients with first recurrent $B M$ were found to be asymptomatic due to screening for potential clinical trials that were conducted at our institution. When BM were identified early, they were typically amenable to potentially radical therapy. In our study, 26 (81\%) of 32 patients had received local treatment for $\mathrm{BM}$. The treatment between the screening group and the "symptomatic first recurrent BM group" did not differ significantly, and about half of each group underwent SRS. Patients in the screening group were associated with longer OS compared with the "symptomatic first recurrent BM group", but with no statistical difference $(p=0.516)$. This difference in survival may be under estimated, given our small sample size and subsequent limited power to calculate the difference in survival. Although current breast cancer screening guidelines do not recommend routine assessment of BM in patients with metastatic disease, our results support consideration of screening for BM in mTNBC patients given the high incidence of BM in TNBC patients with extracranial disease.

Moreover, our result is consistent with previous studies and support the notion that the natural course of BM is also strongly influenced by the biology of the breast cancer subtype. The cause of death in mTNBC patients with $\mathrm{BM}$ is rarely due to progressive intracranial lesions alone, in our study 29\% (37/127), in contrast to HER2positive breast cancer patients with BM, a setting in which up to $50 \%$ of patients die of progressive BM disease [12]. Patients had a prolonged disease control of extracranial disease due to the advancement of active anti-HER2 treatments. Lin NU et al. [12] reported a group of 42 patients treated for BM from mTNBC at Dana-Farber Cancer Institute, only 3 patients were judged to have stable or responsive systemic disease in the face of progressive intracranial disease at the last follow up prior to death. Of the 42 patients, 12 (28.6\%) died primarily of systemic disease progression, 17 (40. $5 \%$ ) died of both systemic and BM progression and only 11 (26.2\%) died primarily of BM progression. Morris et al. [27] found that following diagnosis of BM, 91\% of patients had evidence of progression of the extracranial disease during the course of their disease in their study. Both extracranial disease and BM contribute to the poor survival outcome for mTNBC with BM patients. Since most of the patients with BM from TNBC will have systemic disease progression prior to death, there is an urgent need to develop therapies that are effective in 
systemic therapy rather than close attention to BM alone.

Due to the lack of prospective studies exclusive to $\mathrm{BM}$ in TNBC, there is no specific treatment guidelines for its management. In daily practice, the number of brain lesions, the availability of systemic treatment options, and the presence or absence of extracranial metastases are considered. WBRT has been a mainstay of treatment for several decades [28, 29]. Prolonged survival and better neurocognitive function preservation are due to the high response rate of $60 \%$ after WBRT [30].

However, there are some notable long-term risks of serious and permanent toxic effects, such as cerebellar dysfunction and cognitive deterioration. Nowadays, local therapeutic options as initial treatment are being used with increasing frequency, in order to minimize potential long-term morbidity following WBRT. With tumor number of BM less than four, aggressive local treatments involving either surgical resection or SRS may be applied, with potential curative intentions [31, 32]. The immediate relief of intracranial hypertension and improvement of focal deficits are the additional advantages of surgery and SRS. Nowadays, a local tumor control rate at 1 year of $80-90 \%$ with median survival of $6-$ 12 months has been reported for SRS [30, 33]. Therefore, the number of $\mathrm{BM}$ and the treatment options have significant effect on the survival. In this study, median survival from BM in patients with and without braindirected treatment was 9.5 and 3.7 months, respectively $(p=0.001)$. Median survival of patients underwent WBRT, SRS, WBRT+SRS, surgery and no brain-directed treatment was 8.4, 12.9, 9.3, 11.2 and 3.7 months, respectively. Kaplan-Meier survival analysis indicated that patients with WBRT-based treatment $(n=82)$ exhibited longer OS than patients without WBRT $(n=45)$ (8.7 vs 5.4 months, $p=0.019$ ). Because the numbers were too small, the survival between the subgroup of SRS, SRS+ WBRT, or surgery did not differ significantly.

There are some limitations regarding this study. First, this study was conducted in a single, academic medical center, there might be some referral bias. Second, consistent with clinical practice, triple-negative phenotype was diagnosed on the primary breast tumor and no further re-biopsy of metastatic lesions was performed in the majority of the cases. Therefore, discordance in hormone receptor and HER2 status between primary and metastatic lesions could not be ruled out. To draw a complete picture of this neglected group, prospective studies specifically designed to measure these endpoints other than overall survival are still needed.

\section{Conclusions}

Patients with mTNBC have a high incidence of early $\mathrm{BM}$ with subsequent poor survival. In conclusion, asymptomatic, limited number of metastases, receive any locoregional treatment, first recurrent BM or controlled extracranial metastasis were independent predictors of better survival for mTNBC with BM. The findings lend support to consideration of screening imaging of the brain for mTNBC patients.

\section{Abbreviations}

BM: Brain metastases; Cl: Confidence intervals; DFl: Disease free interval; ER: Estrogen receptor; FISH: Fluorescence in situ hybridization; GPA: Graded prognostic assessment; HER2: Human epidermal growth factor receptor-2; HR: Hazard ratio; IHC: Immunohistochemistry; KPS: Karnofsky performance status; MBC: Metastatic breast cancer; mTNBC: Metastatic Triple negative breast cancer; OS: Overall survival; PgR: Progesterone receptor;

SRS: Stereotactic radiosurgery; WBRT: Whole-brain radiation therapy

\section{Funding}

This study was supported by the Shanghai Municipal Science and Technology Commission Guidance Project, P.R. China (contract no. 14411966000) and Beijing Society for the prevention and treatment of breast cancer research foundation. These funding sources provided support for the conduct of research; they played no role in the design of the study and collection, analysis, interpretation of data, or writing the manuscript.

Availability of data and materials

The dataset of the current study were available from the corresponding author on reasonable request.

\section{Authors' contributions}

$J$ J and YG were responsible for data collection and drafted the manuscript; JZ, LW, BW participated in the design of the study. JJ, YG, JC performed statistic analysis and data interpretation; ZW and ZS designed the study and revised the manuscript. All authors read and approved the final manuscript.

\section{Ethics approval and consent to participate}

This study was conducted inaccordance with the ethical standards of the Declaration of Helsinki and was approved by the Ethics Committee of Fudan University Shanghai Cancer Center. Written human subject consent was not necessary, because this study was based on the retrospective chart review. The institution review board of Fudan University Shanghai Cancer Center approved the waiver.

\section{Competing interests}

The authors declare that they have no competing interest.

\section{Publisher's Note}

Springer Nature remains neutral with regard to jurisdictional claims in published maps and institutional affiliations.

\section{Author details}

${ }^{1}$ Department of Medical Oncology, Fudan University Shanghai Cancer Center, Shanghai 200032, People's Republic of China. ${ }^{2}$ Department of Oncology, Shanghai Medical College, Fudan University, Shanghai, People's Republic of China. ${ }^{3}$ Department of Breast Surgery, Fudan University Shanghai Cancer Center, Shanghai, People's Republic of China. ${ }^{4}$ Shanghai, People's Republic of China.

Received: 14 August 2017 Accepted: 15 April 2018

Published online: 19 April 2018

\section{References}

1. Siegel RL, Miller KD, Jemal A. Cancer Statistics, 2017. CA Cancer J Clin. 2017; 67(1):7-30.

2. Martin AM, Cagney DN, Catalano PJ, Warren LE, Bellon JR, Punglia RS, Claus EB, Lee EQ, Wen PY, Haas-Kogan DA, Alexander BM, Lin NU, Aizer AA. Brain Metastases in Newly Diagnosed Breast Cancer: A Population-Based Study. JAMA Oncol. 2017 Aug 1;3(8):1069-77.

3. Wen PY, Loeffler JS. Brain metastases. Curr Treat Options Oncol. 2000;1(5): 447-58. 
4. Lin NU, Bellon JR, Winer EP. CNS metastases in breast cancer. J Clin Oncol. 2004;22(17):3608-17.

5. Quigley MR, Fukui O, Chew B, Bhatia S, Karlovits S. The shifting landscape of metastatic breast cancer to the CNS. Neurosurg Rev. 2013;36(3):377-82.

6. Bergen ES, Tichy C, Berghoff AS, Rudas M, Dubsky P, Bago-Horvath Z, Mader RM, Exner R, Gnant M, Zielinski CC, Steger GG, Preusser M, Bartsch R. Prognostic impact of breast cancer subtypes in elderly patients. Breast Cancer Res Treat. 2016;157(1):91-9.

7. Heitz F, Harter P, Lueck HJ, Fissler-Eckhoff A, Lorenz-Salehi F, Scheil-Bertram S, Traut A, du Bois A. Triple-negative and HER2-overexpressing breast cancers exhibit an elevated risk and an earlier occurrence of cerebral metastases. Eur J Cancer. 2009;45(16):2792-8.

8. Kennecke $H$, Yerushalmi R, Woods R, Cheang MC, Voduc D, Speers $\mathrm{CH}$ Nielsen TO, Gelmon K. Metastatic behavior of breast cancer subtypes. J Clin Oncol. 2010;28(20):3271-7.

9. Lin NU, Vanderplas A, Hughes ME, Theriault RL, Edge SB, Wong YN, Blayney DW, Niland JC, Winer EP, Weeks JC. Clinicopathologic features, patterns of recurrence, and survival among women with triple-negative breast cancer in the national comprehensive Cancer network. Cancer. 2012;118(22):5463-72.

10. Nieder C, Oehlke O, Hintz M, Grosu AL. The challenge of durable brain control in patients with brain-only metastases from breast cancer. Spring. 2015;4:585.

11. Chowdhury M, Euhus D, Onega T, Biswas S, Choudhary PK. A model for individualized risk prediction of contralateral breast cancer. Breast Cancer Res Treat. 2017;161(1):153-60.

12. Lin NU, Claus E, Sohl J, Razzak AR, Arnaout A, Winer EP. Sites of distant recurrence and clinical outcomes in patients with metastatic triple-negative breast cancer: high incidence of central nervous system metastases. Cancer. 2008 Nov 15:113(10):2638-45.

13. Niwińska A, Murawska M, Pogoda K. Breast cancer brain metastases: differences in survival depending on biological subtype, RPARTOG prognostic class and systemic treatment after whole-brain radiotherapy (WBRT). Ann Oncol. 2008;21(5):942-8.

14. Niwińska A, Pogoda K, Murawska M, Niwiński P. Factors influencing survival in patients with breast cancer and single or solitary brain metastasis. Eur J Surg Oncol. 2011;37(7):635-42.

15. Sperduto PW, Kased N, Roberge D, Chao ST, Shanley R, Luo X, Sneed PK, Suh J, Weil RJ, Jensen AW, Brown PD, Shih HA, Kirkpatrick J, Gaspar LE, Fiveash JB, Chiang V, Knisely JP, Sperduto CM, Lin N, Mehta M. The effect of tumor subtype on survival and the graded prognostic assessment for patients with breast cancer and brain metastases. Int J Radiat Oncol Biol Phys. 2012;82(5):2111-7.

16. Tseng LM, Hsu NC, Chen SC, Lu YS, Lin CH, Chang DY, Li H, Lin YC, Chang HK, Chao TC, Ouyang F, Hou MF. Distant metastasis in triple-negative breast cancer. Neoplasma. 2013;60(3):290-4.

17. Subbiah IM, Lei X, Weinberg JS, Sulman EP, Chavez-MacGregor M, Tripathy D, Gupta R, Varma A, Chouhan J, Guevarra RP, Valero V, Gillbert MR, Gonzalez-Angulo AM. Validation and development of a modified breast graded prognostic assessment as a tool for survival in patients with breast Cancer and brain metastases. J Clin Oncol. 2015;33(20):2239-45.

18. Niikura N, Hayashi N, Masuda N, Takashima S, Nakamura R, Watanabe K, Kanbayashi C, Ishida M, Hozumi Y, Tsuneizumi M, Kondo N, Naito Y, Honda Y, Matsui A, Fujisawa T, Oshitanai R, Yasojima H, Tokuda Y, Saji S, Iwata H. Treatment outcomes and prognostic factors for patients with brain metastases from breast cancer of each subtype: a multicenter retrospective analysis. Breast Cancer Res Treat. 2014;147(1):103-12.

19. Hines SL, Vallow LA, Tan WW, McNeil RB, Perez EA, Jain A. Clinical outcomes after a diagnosis of brain metastases in patients with estrogen- and/or human epidermal growth factor receptor 2-positive versus triple-negative breast cancer. Ann Oncol. 2008;19(9):1561-5.

20. Nam BH, Kim SY, Han HS, Kwon Y, Lee KS, Kim TH, Ro J. Breast cancer subtypes and survival in patients with brain metastases. Breast Cancer Res. 2008;10(1):R20

21. Duchnowska R, Jarząb M, Żebracka-Gala J, Matkowski R, Kowalczyk A, Radecka B, Kowalska M, Pfeifer A, Foszczyńska-Kłoda M, Musolino A, Czartoryska-Arłukowicz B, Litwiniuk M, Surus-Hyla A, Szabłowska-Siwik S, Karczmarek-Borowska B, Debska-Szmich S, Głodek-Sutek B, SosińskaMielcarek K, Chmielowska E, Kalinka-Warzocha E, Olszewski WP, Patera J, Żawrocki A, Pliszka A, Tyszkiewicz T, Rusinek D, Oczko-Wojciechowska M, Jassem J, Biernat W, Polish Brain Metastasis Consortium. Brain metastasis prediction by transcriptomic profiling in triple-negative breast cancer. Clin Breast Cancer. 2017;17(2):e65-75.

22. Dawood S, Lei X, Litton JK, Buchholz TA, Hortobagyi GN, GonzalezAngulo AM. Incidence of brain metastases as a first site of recurrence among women with triple receptor-negative breast cancer. Cancer. 2012;118(19):4652-9.

23. Pestalozzi BC, Zahrieh D, Price KN, Holmberg SB, Lindtner J, Collins J, Crivellari D, Fey MF, Murray E, Pagani O, Simoncini E, Castiglione-Gertsch M, Gelber RD, Coates AS, Goldhirsch A, International Breast Cancer Study Group (IBCSG). Identifying breast cancer patients at risk for central nervous system (CNS) metastases in trials of the international breast Cancer study group (IBCSG). Ann Oncol. 2006;17(6):935-44.

24. Venkitaraman R, Joseph T, Dhadda A, Chaturvedi A, Upadhyay S. Prognosis of patients with triple-negative breast cancer and brain metastasis. Clin Oncol. 2009:21(9):729-30.

25. Krop IE, Lin NU, Blackwell K, Guardino E, Huober J, Lu M, Miles D, Samant M, Welslau M, VM D. Trastuzumab emtansine (T-DM1) versus lapatinib plus capecitabine in patients with HER2-positive metastatic breast cancer and central nervous system metastases: a retrospective, exploratory analysis in EMILIA. Ann Oncol. 2015;26(1):113-9.

26. Metro G, Foglietta J, Russillo M, Stocchi L, Vidiri A, Giannarelli D, Crinò L, Papaldo P, Mottolese M, Cognetti F, Fabi A, Gori S. Clinical outcome of patients with brain metastases from HER2-positive breast cancer treated with lapatinib and capecitabine. Ann Oncol. 2011;22(3):625-30.

27. Morris PG, Murphy CG, Mallam D, Accordino M, Patil S, Howard J, Omuro A, Beal K, Seidman AD, Hudis CA, Fornier MN. Limited overall survival in patients with brain metastases from triple negative breast cancer. Breast J. 2012;18(4):345-50

28. Aoyama H, Shirato H, Tago M, Nakagawa K, Toyoda T, Hatano K, Kenjyo M, Oya N, Hirota S, Shioura H, Kunieda E, Inomata T, Hayakawa K, Katoh N, Kobashi G. Stereotactic radiosurgery plus whole-brain radiation therapy vs stereotactic radiosurgery alone for treatment of brain metastases: a randomized controlled trial. JAMA. 2006;295(21):2483-91.

29. Eichler AF, Loeffler JS. Multidisciplinary management of brain metastases. Oncologist. 2007;12(7):884-98.

30. Soffietti R, Rudà R, Trevisan E. Brain metastases: current management and new developments. Curr Opin Oncol. 2008:20(6):676-84.

31. Leone JP, Leone BA. Breast cancer brain metastases: the last frontier. Exp Hematol Oncol. 2015:4:33.

32. Liu MC, Cortés J, O'Shaughnessy J. Challenges in the treatment of hormone receptor-positive, HER2-negative metastatic breast cancer with brain metastases. Cancer Metastasis Rev. 2016;35(2):323-32.

33. Mehta MP, Tsao MN, Whelan TJ, Morris DE, Hayman JA, Flickinger JC, Mills M, Rogers CL, Souhami L. The American Society for Therapeutic Radiology and Oncology (ASTRO) evidence-based review of the role of radiosurgery for brain metastases. Int J Radiat Oncol Biol Phys. 2005;63(1):37-46.

\section{Ready to submit your research? Choose BMC and benefit from:}

- fast, convenient online submission

- thorough peer review by experienced researchers in your field

- rapid publication on acceptance

- support for research data, including large and complex data types

- gold Open Access which fosters wider collaboration and increased citations

- maximum visibility for your research: over $100 \mathrm{M}$ website views per year

At BMC, research is always in progress.

Learn more biomedcentral.com/submissions 